In this book much solid evidence is presented in an interesting fashion that deserves careful study.

\title{
Dynamics of Even-aged Forest Stands
}

J. H. G. SмrтH

By M. S. Czarnowski, 1961. Louisiana State Univ. Press, Baton Rouge, La., $132 \mathrm{pp} ., \$ 5.00$.

This important book expresses and explains in a comprehensive fashion the influences of normal density of stocking (crowding) on mean tree height, and mean tree diameter. The theory examined mathematically by the author to account for forest-stand dynamics contains two main parts: "1. In pure, even-aged stands of a given species growing on land of identical site quality and under conditions of comparable competition for growing space, the number of trees per unit of land area is inversely proportional to the square of the mean height of the stand. 2. The average diameter breast high in a stand is directly proportional to the mean stand height reduced by the height of measurement of diameter and inversely proportional to a "crowding" factor enlarged by the value 1."

Most of the assumptions demonstrated mathematically and with empirical data are worthy of careful study by anyone seriously interested in putting more science into the art of silviculture. The idea of crown-length ratio as a function of crowding and compactness factors is expressed well.

It is to be hoped that the author will extend his analyses to include the concept of maximum crown area of fully open grown trees setting a limit to growth rate which supplements the idea of the normal stand. Similarly the crown-length ratio might be compared with ratios of crown width to d.b.h. and height to crown width which are convenient measures of density.

\section{Measure for Measure}

J. H. G. SMITH

By P. J. Rennie, Dept. of Forestry, For. Res. Br., Chalk River, Ontario, Mimeo. 43 p., free.

Dr. Rennie has assembled an up-to-date readily available source of measurements likely to be encountered in forest science. Useful conversion factors are summarized for angular measurement, length, area, volume, weight, proportion, velocity, flow, pressure, energy, and temperature.

\section{Recreational Use of Wild Lands}

By C. Frank Brockman, 1959. McGraw-Hill Co., 253 Spadina Road, Toronto 4, 346 p., $\$ 10.75$.

Professor Brockman has provided a broad, basic outline of the background, importance, values, and fundamental requirements of the recreational management of wild lands. His ideas and the literature he has cited provide an essential starting point for the development of well informed interest by forest managers in forest recreation. He has achieved his hope: His book "will aid in the development of the broad perspective necessary to greater appreciation of the many recreational values of wild land, so that the objectives of their use may be most economically realized and properly coordinated with other requirements of modern life."

In spite of the fact that most of us were attracted to forestry initially by an interest in the out-of-doors few Canadian foresters have given serious study 